\title{
Simulasi Starter Mobil Dengan Kontrol Suara Menggunakan Android Model Berbasis Mikrokontroler
}

\author{
Yul Antonisfia ${ }^{1}$, Andrizal $^{2}$, Rio Fernando Aditama ${ }^{3}$ \\ ${ }^{123}$ Jurusan Teknik Elektro Politeknik Negeri Padang \\ yulantonisfia@pnp.ac.id \\ Kampus Politeknik Negeri Padang, Limau Manis Padang
}

\begin{abstract}
Current technological advances make it easier for vehicle users. The use of keys on the vehicle can be replaced with sound with the right command. This simulation uses an Arduino Uno 328 microcontroller to process data after a voice command from android. This simulation also uses a Bluetooth module as a link between the Arduino Microcontroller and Android. The voice command entered into the android will send data to the microcontroller, and then relay 1 as the indicator will light up (the car's contact state turns on in the simulation), and when the command to turn on the car relay 2 will turn on (the car starter is on in simulation). And the last command to turn off the two relay indicators (the state of the car is turned off in the simulation).
\end{abstract}

Keywords: Microcontroller, Android, Relay, Bluetooth Module.

\begin{abstract}
Abstrak - Kemajuan teknologi saat ini memudahkan pengguna kendaraan. Penggunaan kunci pada kendaraan bisa tergantikan dengan suara dengan perintah yang tepat. Simulasi ini menggunakan mikrokontroler Arduino Uno 328 untuk memproses data setelah adanya perintah suara dari android. Simulasi ini juga menggunakan modul Bluetooth sebagai penghubung antara Mikrokontroler Arduino dan Android. Perintah suara yang di masukan ke android akan mengirimkan data ke mikrokontroler, dan kemudian relay 1 sebagai indikator akan menyala (keadaan kontak mobil menyala dalam simulasi), dan ketika perintah untuk menghidupkan mobil maka relay 2 akan menyala (keadaan starter mobil menyala dalam simulasi). Dan perintah terakhir untuk mematikan kedua relay indikator (keadaan mobil dimatikan dalam simulasi).
\end{abstract}

Kata kunci: Mikrokontroller, Android, Relay, Modul Bluetooth.

(C) 2017 Elektron Jurnal Ilmiah

\section{I.PENDAHULUAN}

Dengan adanya kemajuan teknologi dalam bidang pengolahan sinyal digital (Digital Signal Processing) telah membawa dampak positif dalam kehidupan manusia. Pengolahan sinyal digital telah banyak digunakan dalam berbagai aplikasi. Sebagai contoh, aplikasi-aplikasi tersebut meliputi teknik pengenalan suara, kompresi sinyal (data, gambar), dan juga televisi dan telepon digital. Teknologi pengenalan ucapan (speech recognition) merupakan salah satu teknologi biometrika yang tidak memerlukan biaya besar serta peralatan khusus. Pada dasarnya setiap manusia memiliki sesuatu yang unik/khas yang hanya dimiliki oleh dirinya sendiri. Suara merupakan salah satu dari bagian tubuh manusia yang unik dan dapat dikenali dengan mudah. Disamping itu, sistem biometrika suara memiliki karakteristik seperti, tidak dapat lupa, tidak mudah hilang dan tidak mudah untuk dipalsukan karena keberadaannya melekat pada diri manusia sehingga keunikannya lebih terjamin.

Speech recognition system adalah suatu proses pengenalan ucapan berupa kata yang memungkinkan pengguna untuk memberikan masukan atau perintah ke aplikasi dengan suara. Manusia tidak perlu lagi menggunakan kunci, hanya dengan menggunakan suaranya manusia dapat menyalakan dan mematikan mobil. Pengenalan suara merupakan salah satu teknik penting dalam mengembangkan user-friendly interface untuk interaksi manusia-komputer. Speech recognition akan dirancang dengan menggunakan Smartphone Android yang sudah disediakan pada sebuah program dari APP Inventor. Penulis akan menggunakan sebuah mikrokontroller arduino sebagai pusat kontrolnya, agar suara dapat mengontrol starter mobil.

Pada sistem pengenal ucapan ini, para pengguna mobil cukup menggunakan kata kunci yang telah dirancang sebelumnya seperti "Nyala". Berdasarkan latar belakang tersebut pada penelitian ini dirancanglah sistem Simulasi Starter Mobil Dengan Kontrol Suara Menggunakan Android Model Berbasis Mikrokontroler. Penelitian yang terkait sebelumnya pernah dilakukan. Efrianto.dkk[1] menggunakan RFID dengan frekuensi 13,56 HZ sebagai pengganti kontak motor Setiap satu kontak kendaraan hanya dapat menggunakan satu smartcard dan dapat menggunakan penggantian kartu apabila kepemilikan kendaraan berpindah dengan adanya sistem registrasi pada alat ini. Dwi Ely Kurniawan, dkk[2] dalam penelitiannya menggunakan sensor getar untuk keamanan sepeda motor, sensor akan mengirimkan getaran ke output mikrokontroler raspberry pi dan kemudian mengirim pesan pemberitahuan peringatan. Pemilik kendaraan 
akan segera mengendalikan sepeda motor saat terjadi pencurian menggunakan aplikasi android.

Tujuan dari penelitian ini adalah merancang dan membuat sebuah sistem kontrol suara yang mampu mengenali dengan tepat perintah yang diberikan oleh user dengan metode Smarphone Android menggunakan APP Inventor dan membuat sebuah sistem yang mampu menerjemahkan perintah dari user untuk simulasi menyalakan dan mematikan Indikator relay dan led.

\section{METODE PENELITIAN}

Metode yang digunakan dalam penelitian ini adalah pembuatan protype alat yang dimulai dari perancangan system yang akan disusun dan direalisasikan dalam sebuah objek atau alat yang akan dirancang. Dalam proses perancangan alat ini terbagi dalam tiga tahapan yaitu :

1. Membuat blok diagram rangkaian.

2. Perancangan perangkat keras (hardware).

3. Perancangan perangkat lunak (software).

\subsection{Blok Diagram Rangkaian}

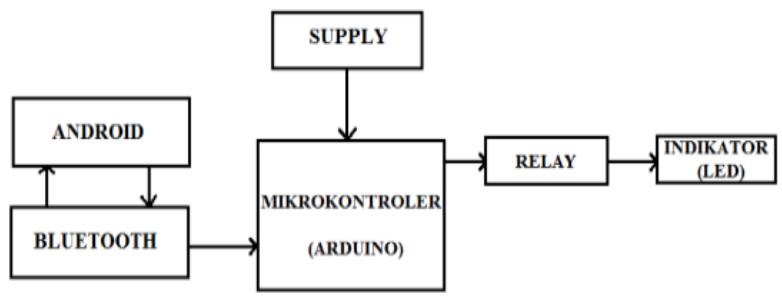

Gambar 1. Blok Diagram Rangkaian

Dari blok diagram diatas dapat dilihat konfigurasi dari prinsip kerja sistem starter otomatis pada mobil yang terdiri dari input, kontroller, dan output. Input terdiri dari perintah suara yang melakukan speech recognation pada android, kontrol yang digunakan adalah Arduino, dan outputnya adalah relay dan starter mobil. Prinsip kerja alat ini secara garis besar adalah android harus menghidupkan koneksi bluetooth $\neg$ terlebih dahulu dengan program yang dibutuhkan. Untuk terhubung ke mikrokontroller, android harus melakukan pairing dengan bluetooth melalui aplikasi yang telah ada. Setelah terhubung ke mikrokontroller maka android siap untuk menerima dan melakukan perintah yang di berikan user.

Jika perintah yang di berikan sesuai dengan program diatur maka akan mengaktifkan relay 1 sebagai simulasi alat akan menyala. Begitu juga dengan perintah untuk mengaktifkan relay 2 sebagai simulasinya. Dan ketika perintah untuk mematikan simulasi sesuai dengan program yang diatur maka keuda relay akan mati dan simulasi alat dalam keadaan tidak menyala. Hasil pengujian dari mengaktifkan dan mematikan alat simulasi starter mobil dapat dilihat pada tabel 1 .

Tabel 1. Hasil pengujian dari mengaktifkan dan mematikan alat simulasi starter mobil

\begin{tabular}{ccccc}
\hline $\begin{array}{c}\text { Perintah } \\
\text { Suara }\end{array}$ & $\begin{array}{c}\text { Relay 1 } \\
\text { (Kontak } \\
\text { Mobil) }\end{array}$ & $\begin{array}{c}\text { Relay } \\
2\end{array}$ & $\begin{array}{c}\text { Led } \\
\text { (Starter } \\
\text { Mobil) }\end{array}$ & $\begin{array}{c}\text { Led } \\
1\end{array}$ \\
\hline Alex & Aktif & Mati & Aktif & Mati \\
\hline Alex hidup & Aktif & Aktif & Aktif & Aktif \\
\hline Alex mati & Mati & Mati & Mati & Mati \\
\hline
\end{tabular}

\subsection{Perancangan Perangkat Keras}

Rangkaian shiled board mikrokontroler Arduino Uno dibuat untuk mempermudah pengkabelan dan juga untuk menempatkan input dan output pada alat. Pada perancangan tugas akhir ini menggunakan rangkaian Shield untuk menghubungkan arduino dengan rangkaian lainnya. Tegangan input (Vin) pada arduino menggunakan adaptopr $18 \mathrm{~V}$. Shield ini menggunakan IC 7805 sebagai tegangn ke relay dan IC 7812 sebagai penurun tegangan untuk input ke arduino. Pin yang digunakan untuk Bluetooth adalah sumber $5 \mathrm{~V}$ (Vcc) dan terhubung ke ground, kemudian pada transmiter dan reciever sebagai penerima sinyal.

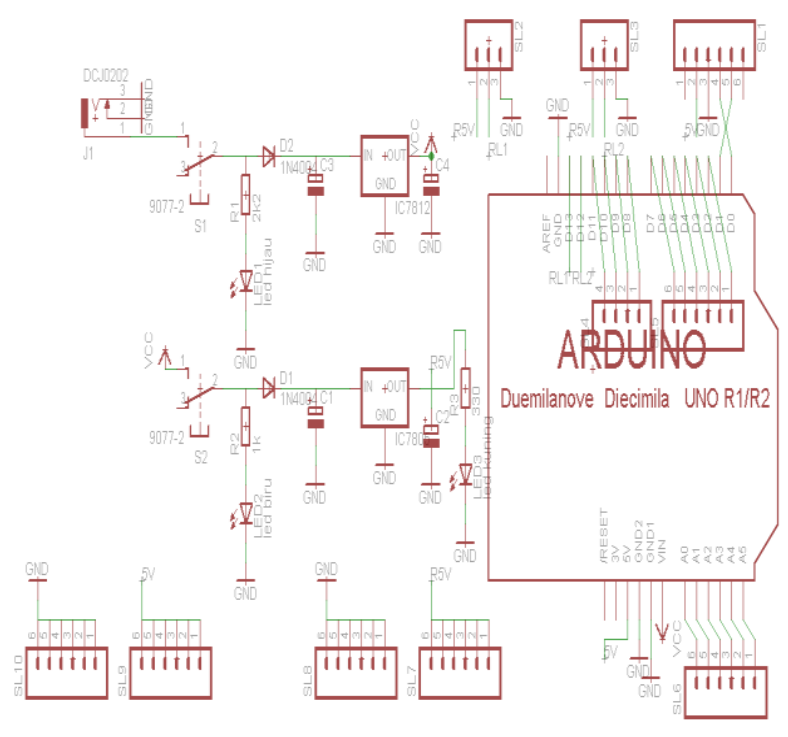

Gambar 2. Rangkaian Shield Arduino

Pada rangkaian ini Pin 10 dan 11 merupakan output dari proses yang dijalankan. Output dari Arduino akan terhubung ke relay, lalu relay dihubungkan ke led untuk memperjelas output yang di hasilkan dari simulasi starter mobil otomatis. Adapun pin-pin input ouptut pada mikrokontroler dapat dilihat pada tabel 2 berikut : 
Tabel 2. Pin-Pin Input Output pada Mikrokontroler

\begin{tabular}{|c|c|c|}
\hline Bagian & Pin & Kegunaan \\
\hline Reciever & $\mathrm{Rx}$ & $\begin{array}{l}\text { Reciever }(\mathrm{Rx}) \text { berfungsi sebagai } \\
\text { penerima data dari perintah yang di } \\
\text { inputkan dari android ke } \\
\text { mikrokontroler. }\end{array}$ \\
\hline Transmitter & $\mathrm{Tx}$ & $\begin{array}{l}\text { Transmitter (Tx) berfungsi sebagai } \\
\text { pengirim data dari mikrokontroler } \\
\text { ke android. }\end{array}$ \\
\hline Relay 1 & 10 & $\begin{array}{l}\text { Relay } 1 \text { berfungsi sebagai output } \\
\text { dari simulasi yang dilakukan, jika } \\
\text { perintah yang di lakukan sesuai } \\
\text { dengan program maka relay akan } \\
\text { berlogika high dan led akan } \\
\text { menyala. Indikator ini menyala } \\
\text { untuk menghidupkan kontak mobil } \\
\text { pada simulasi ketika perintah } \\
\text { "Alex". }\end{array}$ \\
\hline Relay 2 & 11 & $\begin{array}{l}\text { Relay } 2 \text { berfungsi sebagai sebagai } \\
\text { output dari simulasi yang dilakukan, } \\
\text { jika perintah yang di lakukan sesuai } \\
\text { dengan program maka relay akan } \\
\text { berlogika high dan led akan } \\
\text { menyala. Indikator ini menyala } \\
\text { untuk menghidupka mobil pada } \\
\text { simulasi ketika perintah “Alex } \\
\text { hidup” }\end{array}$ \\
\hline
\end{tabular}

\subsection{Perancangan Perangkat Lunak}

Perangkat lunak yang digunakan pada simulasi alat ini adalah arduino dan app inventor. Pada perancangan program di arduino untuk menghubungkan mikrokontroller dengan android dan rangkaian lain yang digunakan. APP Inventor sendiri digunakan segabai pembuat aplikasi program yang di jalankan oleh android itu sendiri. Dengan kedua program yang telah diatur maka simulasi ini akan bisa digunakan menggunakan perintah suara.

\subsection{Flowchart Program}

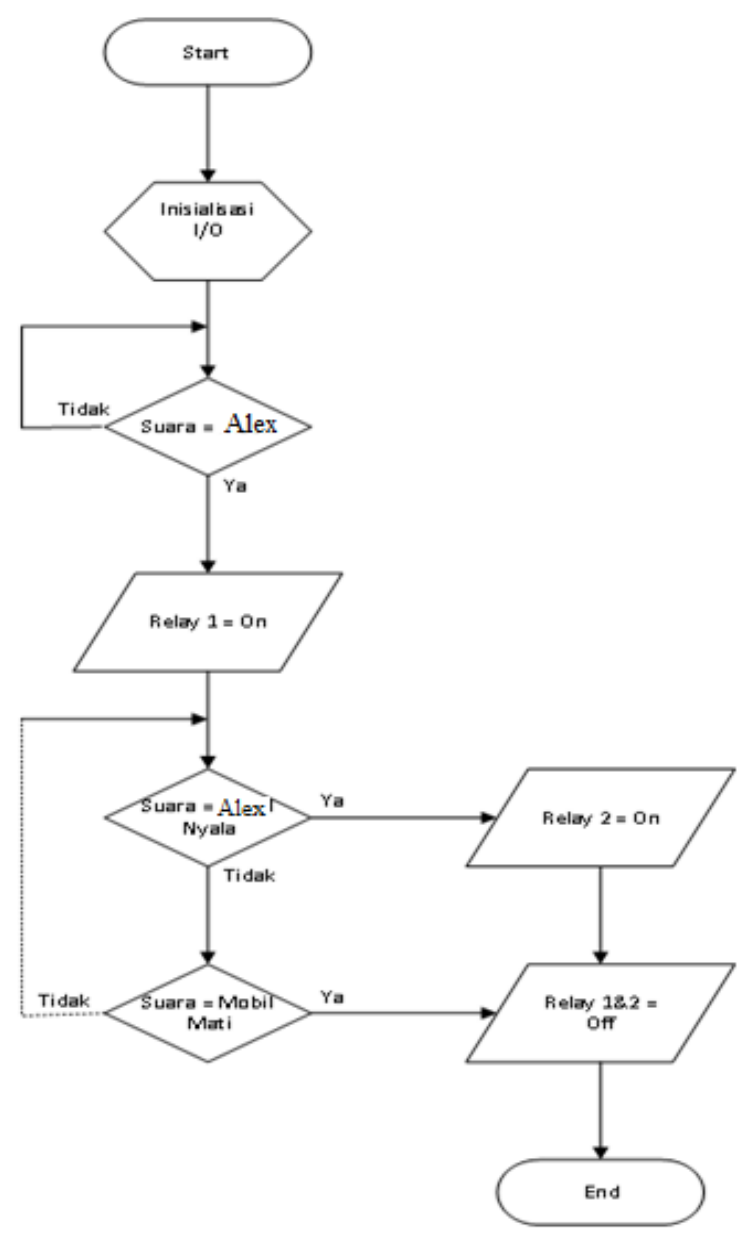

Gambar 3. Flowchat Program

Adapun penjelasan dari Flowchart sistem ini adalah ketika input suara diperintahkan "Alex" maka sistem akan mengaktifkan relay 1 sebagai output bahwa kelistrikan mobil telah hidup secara simulasi. Kemudian Ketika untuk perintah selanjutnya dengan input suara "Alex hidup" maka sistem akan mengaktfkan relay 2 sebagai output bahwa starter mobil telahaktif secara simulasi. Perintah untuk menghidukan stareter mobil harus di dahului oleh menghidupkan kelistrikan mobil terlebih dahulu. Untuk perintah selanjutnya yaitu mematikan mobil dengan input suara "Alex mati", maka akan mematikan relay 1 dan relay 2 dan simulasi mobil akan mati.

\section{HASIL DAN PEMBAHASAN}

Pengujian dilakukan dengan dua tahap, yaitu pengujian terpisah bagian per bagian dan pengujian sistim secara keseluruhan, dengan penjabaran sebagai berikut. Alat ini menggunakan Adaptor yang memiliki tegangan sevbesar $18 \mathrm{~V}$ DC. Pada rangkaian IC regulator 7805 tegangan $18 \mathrm{~V}$ DC akan diubah menjadi 5V DC yang akan di alirkan ke arduino. Kemuadian IC 7812 akan mengalirkan tegangan sebesar 5V DC ke modul relay. Alat ini bekerja jika ada seseorang 
memiliki program yang telah terdaftar pada androidnya dan telah terhubung dengan alat melakukan perintah sebagai mana yang telah di program. Untuk mengaktifkan simulasi mobil perintah yang harus di ucapkan adalah "mobil". Untuk menghidupkan simulasi mobil perintah yang harus diucapkan adalah "mobil nyala". Simulasi mobil akan nyala ketika dimana perintah untuk mengaktifkan simulasi mobil telah di lakukan. Kemudian untuk mematikan simulasi mobil ini dengan perintah "mobil mati".

\subsection{Pengujian Pada Rangkaian Bluetooth}

Pengukuran pada rangkaian penghubung antara mikrokontroller dengan android berfungsi untuk mengetahui seberapa jauh rangkaian ini bisa bekerja. Tabel 3 merupakan hasil Bluetooth HC 05 dengan menggunakan Android.

Tabel 3. Hasil Pengujian Bluetooth HC 05 dengan menggunakan Android

\begin{tabular}{ccc}
\hline Percobaan & $\begin{array}{c}\text { Jarak } \\
\text { (meter) }\end{array}$ & Hasil \\
\hline 1 & 2 & Terhubung \\
\hline 2 & 4 & Terhubung \\
\hline 3 & 6 & Terhubung \\
\hline 4 & 8 & Terhubung \\
\hline 5 & 10 & Terhubung \\
\hline 6 & 12 & Putus-putus \\
\hline 7 & 14 & Putus-putus \\
\hline 8 & 16 & Terputus \\
\hline 9 & 18 & Terputus \\
\hline 10 & 20 & Terputus \\
\hline
\end{tabular}

Dari hasil pengukuran yang dilakukaan di area tanpa hambatan diperoleh hasil dari tabel di atas diketahui bahwa bluetooth $\mathrm{HC}-05$ hanya dapat mengirim data maksimal dengan jarak 12 meter setelah menempuh jarak lebih dari 16 meter pengiriman data kurang maksimal. Jarak yang terdeteksi pada bluetooth dapat terganggu karena hambatan yang terjadi disekitarnya, hambatan yang terjadi dapat berupa gangguan frekuensi atau peralatan elektronik lainnya yang dapat memperlambat proses pengiriman data, perangkat lunak yang digunakan, konfigurasi dari perangkat dan kondisi dari sinyal itu sendiri.

Dari hasil pengukuran yang dilakukaan di area terhalang tembok diperoleh hasil dari tabel di atas diketahui bahwa bluetooth HC-05 hanya dapat mengirim data maksimal dengan jarak 10 meter setelah menempuh jarak lebih dari 16 meter pengiriman data kurang maksimal. Jarak yang terdeteksi pada bluetooth dapat terganggu karena hambatan yang terjadi disekitarnya. Pengujian jarak pada bluetooth dilakukan dengan menggunakan HP android Tipe Samsung Core 2 dengan aplikasi app invetor yang sudah terpasang dan terkoneksi pada rangkaian, pengukuran ini dilakukan bertujuan untuk menguji jarak maksimal yang dapat dicapai oleh koneksi bluetooth tersebut.

\subsection{Pengujian Pada Rangkaian Relay}

Pengukuran rangkaian pemutus data dengan relay berfungsi untuk mengetahui apakah relay berfungsi atau tidak. Berikut titik pengukuran pada rangkaian relay.

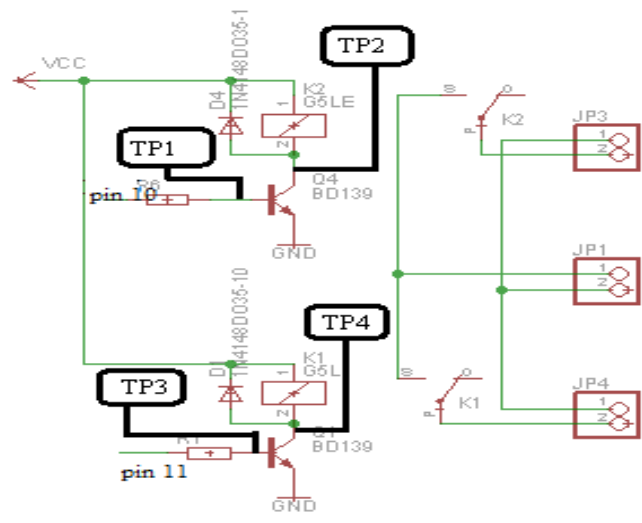

Gambar 4. Titik Pengukuran pada rangkaian relay

Hasil pengukuran relay dapat dilihat di tabel 4 berikut ini :

\begin{tabular}{|c|c|c|c|c|c|}
\hline $\begin{array}{l}\text { Transis } \\
\text { tor }\end{array}$ & $\begin{array}{l}\text { Titik } \\
\text { penguku } \\
\text { ran }\end{array}$ & $\begin{array}{l}\mathrm{Cu} \\
\mathrm{t} \\
\text { off } \\
(\mathrm{V} \\
)\end{array}$ & $\begin{array}{l}\text { Satur } \\
\text { asi } \\
\text { (V) }\end{array}$ & $\begin{array}{l}\mathrm{C} \\
\mathrm{ut} \\
\text { of } \\
\mathrm{f} \\
\text { (A } \\
\text { ) }\end{array}$ & $\begin{array}{l}\text { Satur } \\
\text { asi } \\
\text { (A) }\end{array}$ \\
\hline \multirow[t]{2}{*}{ TR1 } & $\begin{array}{l}\mathrm{TP} 1 \\
\left(\mathrm{~V}_{\mathrm{BE}}\right)\end{array}$ & $\begin{array}{l}0,2 \\
\text { Vo } \\
\text { lt }\end{array}$ & $\begin{array}{l}0,8 \\
\text { Volt }\end{array}$ & \multirow{2}{*}{$\begin{array}{l}\mathrm{I}_{\mathrm{C}} \\
= \\
0 \\
\mathrm{~A}\end{array}$} & \multirow[t]{2}{*}{$\begin{array}{l}\mathrm{I}_{\mathrm{C}}=5 \\
\mathrm{~mA}\end{array}$} \\
\hline & $\begin{array}{l}\mathrm{TP} 2 \\
\left(\mathrm{~V}_{\mathrm{CE}}\right)\end{array}$ & $\begin{array}{l}5 \\
\text { Vo } \\
\text { lt }\end{array}$ & $\begin{array}{l}0,26 \\
\text { Volt }\end{array}$ & & \\
\hline \multirow[t]{2}{*}{ TR2 } & $\begin{array}{l}\mathrm{TP} 3 \\
\left(\mathrm{~V}_{\mathrm{BE}}\right)\end{array}$ & $\begin{array}{l}0,2 \\
\text { Vo } \\
\text { lt }\end{array}$ & $\begin{array}{l}0,7 \\
\text { Volt }\end{array}$ & \multirow{2}{*}{$\begin{array}{l}\mathrm{I}_{\mathrm{C}} \\
= \\
0 \\
\mathrm{~A}\end{array}$} & \multirow{2}{*}{$\begin{array}{l}\mathrm{I}_{\mathrm{C}}= \\
4,5 \\
\mathrm{~mA}\end{array}$} \\
\hline & $\begin{array}{l}\mathrm{TP} 4 \\
\left(\mathrm{~V}_{\mathrm{CE}}\right)\end{array}$ & $\begin{array}{l}5 \\
\text { Vo } \\
\text { lt }\end{array}$ & $\begin{array}{l}0,26 \\
\text { Volt }\end{array}$ & & \\
\hline
\end{tabular}

Rangkaian relay merupakan rangkaian yang berfungsi untuk saklar automatis dengan memanfaatkan transistor sebagai saklar. Apabila transistor dalam keadaan cut offtegangan yang didapat pada VBE (TP1 dan TP3) di transistor 1 dan 2 adalah 0,2 Volt dan tegangan yang didapat pada VCE(TP2 dan TP4)di transistor 1 dan 2 adalah 5 Volt. ketika transistor dalam keadaan saturasi tegangan pada VBE (TP1) di transistor 1 adalah 0,8 Volt sedangkan VBE (TP3) di transistor 2 adalah 0,7 Volt. Kemudian pada pengukuran VCE (TP3 dan TP5) di transistor 1 dan 2 di dapatkan 0,26 Volt. 


\subsection{Pengujian Pada Aplikasi Android}

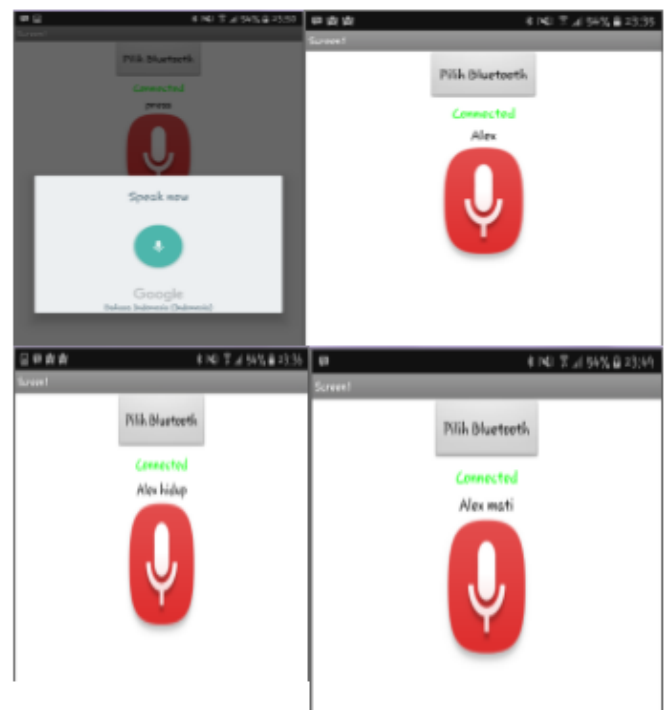

Gambar 5. Pengujian pada aplikasi android

Hasil pengujian Aplikasi APP Inventor pada android dapat dilihat pada tabel berikut ini:

Tabel 5. Hasil Pengujian APP inventor

\begin{tabular}{ccc}
\hline $\begin{array}{c}\text { Perintah } \\
\text { Suara }\end{array}$ & $\begin{array}{c}\text { Hasil yang } \\
\text { tampil }\end{array}$ & Indikator \\
\hline Alex & Alex & Relay1 = On \\
\hline Alex Hidup & Alex hidup & Relay $2=$ On \\
\hline Alex Mati & Alex mati & Relay $1 \& 2=$ Off \\
\hline
\end{tabular}

Android dengan perintah suara yang di masukkan akan secara langsung melakukan proses speech recognition (pegenalan ucapan) dimana ucapak user akan diubah menjadi data berbentuk text. Sehingga hasil yang tampil akan sesuai dengan apa yang user ucapkan. Sehingga perintah bisa langsung di kenali oleh program. Dengan adanya bantuan dari APP Inventor yang langsung memproses ucapan mejadi text. Setelah proses getting text maka ucapan user akan di tampilkan dalam bentuk text, dan dikirimkan ke mikrokontroler.

\section{KESIMPULAN}

Dari hasil pengujian dan analisa pada simulasi starter otomatis pada mobil yang tellah dibuat maka dapat di ambil kesimpulan sebagai berikut :
1. Alat ini mampu malakukan simulasi starter mobil otomatis menggunakan perintah suara dengan perintah yang telah diatur sedemikian rupa pada programnya.

2. Proses pengiriman dan penerimaan data dari android di hubungkan dengan Bluetooth.

3. Dengan melakukan sistem starter menggunakan perintah suara akan memudahkan pengguna mobil dan tidak meminimalisir resiko kehilangan kunci ataupun mobil dicuri orang. Karena untuk menghidupkan mobil harus memiliki aplikasi yang dibutuhkan pada androidnya.

\section{REFERENSI}

[1] Efrianto, Ridwan, Iman Fahruzi. 2016. Sistem Pengaman Motor Menggunakan Smartcard Politeknik Negeri Batam. Jurnal Integrasi Vol. 8, No. 1, April 2016, 01-05

[2] Dwi Ely Kurniawan , Muhamad Naharus Surur. 2016. Perancangan Sistem Pengamanan Sepeda Motor Menggunakan Mikrokontroler Raspberry Pi dan Smartphone Android. Jurnal Komputer Terapan Vol 2. No. 2, November 2016, 93-104

[3] Rino Reifano Rachmat, E. Shintadewi Julian.2016. Pengaman Sepeda Motor Berbasis Mikrokontroler. JETri, Volume 13, Nomor 2, Februari 2016, Hal 1 - 10.

[4] Kurnia Dwi Artika. 2013. Rancang Bangun Sistem Pengaman Pada Sepeda Motor Dengan Memanfaatkan Sensor Encoder Dan Sensor Ping. Jurnal ROTOR, Volume 6 Nomor 1, Januari 2013.

[5] Dwi Ely Kurniawan, Muhamad Naharus Surur. 2017. Sistem Pengaman Sepeda Motor Berbasis Perangkat Bergerak dengan Notifikasi dan Kendali Mesin. Jurnal Sistem Informasi (JSI), VOL.9, NO.1, April 2017, hal: 1159-1165.

[6] Chen Peijian and Jiang Xuehua.2008. Design and Implementation of Remote Monitoring System Based on GSM. in IEEE PacificAsia Workshop on Computational Intelligence and Industrial Application, 2008, pp. 678-681.

[7] Kedi Wadenla M. S,Kom 2014. Perancangan dan Implementasi Starter Mobil Menggunakan Suara dengan Metode Hidden Markov Model Berbasis Komputer Mini. 